\title{
COMPARISON OF METHODS USED FOR SEISMIC ANALYSIS OF STRUCTURES
}

\author{
PETR ČADA*, JiŘí MÁCA \\ Czech Technical University in Prague, Faculty of Civil Engineering, Thákurova 7, 16629 Prague 6, Czech \\ Republic \\ * corresponding author: petr.cada@fsv.cvut.cz
}

\begin{abstract}
This paper investigates effects of the seismic load to a structure. The article describes main methods of the definition and practical application of the seismic load based on the Standard Eurocode 8. There was made a comparison of all methods using the same structure. A simple two-storeyed concrete 2D-frame with fixed joints was chosen. A one another model with rigid beams for some calculations was defined. The second model can be used for hand-calculations as a cantilever with two masses.

The paper describes main dynamic properties of the chosen structure. Seismic load was defined by lateral force method, modal response spectrum, non-linear time-history analysis and pushover analysis. The time-history analysis is represented by accelerograms. There were made linear and non-linear calculations.
\end{abstract}

KEYWORDS: seismic response, lateral force method, response spectrum, time-history analysis, pushover analysis.

\section{INTRODUCTION}

For a calculation of the seismic response, the linear state of stress is commonly used. By complicated cases or by higher importance of the structure is recommended to use some non-linear method. In Eurocode 8 (EC8) [1] these four methods of analysis are defined:

- Lateral force method,

- Modal response spectrum analysis,

- Non-linear time-history (dynamic) analysis,

- Non-linear static (pushover) analysis.

For the better results of the behaviour of the structure, there is necessary to use one of the non-linear methods. The ductility is the most important property for a non-linear calculation. The ductility describes the behaviour of the plastic deformations, which cause irreversible deformations and this fact can be used for the reduction of the seismic load.

Calculations in this article describe the possibilities of the EC8 [1]. For this purpose, a two-storeyed concrete frame with a uniformly distributed load was used. This simple structure was chosen because of the possibility to applicate all methods. Only a simple model can fulfil all conditions of all methods.

Lateral force method is a static and linear (linear behaviour of the material) calculation using horizontal forces as a seismic load. By this method a high frequency cannot have the decisive influence. The base shear force can be defined for each direction. Distribution of horizontal forces is linear increasing or responds to the eigenvalues. The each storey must be rigid in its plane [1].
Modal response spectrum analysis is a dynamic method with the same geometrical rules as by the lateral force method. For the horizontal displacement, all decisive eigenmodes should be used, but at least $90 \%$ of the total mass. Responses from different directions can be combined by the SRSS (square root of the sum of the squares) or CQC (complete quadric combination) method. This is possible only when eigenmodes are mutually independent [1]. Worked examples for lateral force method and modal response spectrum are shown in [2].

Non-linear time-history (dynamic) analysis is based on direct numerical integration of the differential equation of motion. Motion of the base is represented by the accelerogram [1]. This method is described in [3, 4] as well.

Non-linear static (pushover) analysis is the last type of the seismic calculations from the EC8 [1]. In this standard, the most used version - N2 method - is used. The name was derived from "nonlinear" for "N" and "2" for two mathematical models. Method was developed by Prof. Peter Fajfar. Three steps of analysis are defined. The first step is used for determination of the stiffness, strength and ductility of the structure. The first mathematical model - MDOF (multiple degree of freedom) system - with linear increasing horizontal load is used. For the structure, an equivalent SDOF (single degree of freedom) system in the second step must be defined. The behaviour must be same as by the MDOF system. The ratio between base shear force and the top-displacement is the base for the non-linear characteristics. The maximal displacement is calculated in the third step by the SDOF system. The pushover analysis is regularly used for the first eigenmode (the first eigenmode must 
be decisive), but theoretically is it possible to use this method for any eigenmod [5. For example [6 9 are dealing with this issue as well.

\section{Structure AND LOAD}

\subsection{MODEL OF THE STRUCTURE AND MATERIAL PARAMETERS}

For sample-calculations of the response to the seismic load, a simple two-storeyed concrete frame with fixed joints was chosen. The width is $6 \mathrm{~m}$ and the height is $4 \mathrm{~m}$ for one storey. The total height is $8 \mathrm{~m}$.

The frame consists of two cross-sections. Columns are square cross-section of the dimension $40 \times 40 \mathrm{~cm}$. The reinforcement is distributed symmetrical to all sides and the bar diameter is $\varnothing 20$. Cross-beams are rectangular cross-section of the dimension $40 \times 60 \mathrm{~cm}$ and the reinforcement is placed only at the bottom and on the top of cross-section. It is used $3 \varnothing 20$ for one side. The shear-reinforcement is not considered.

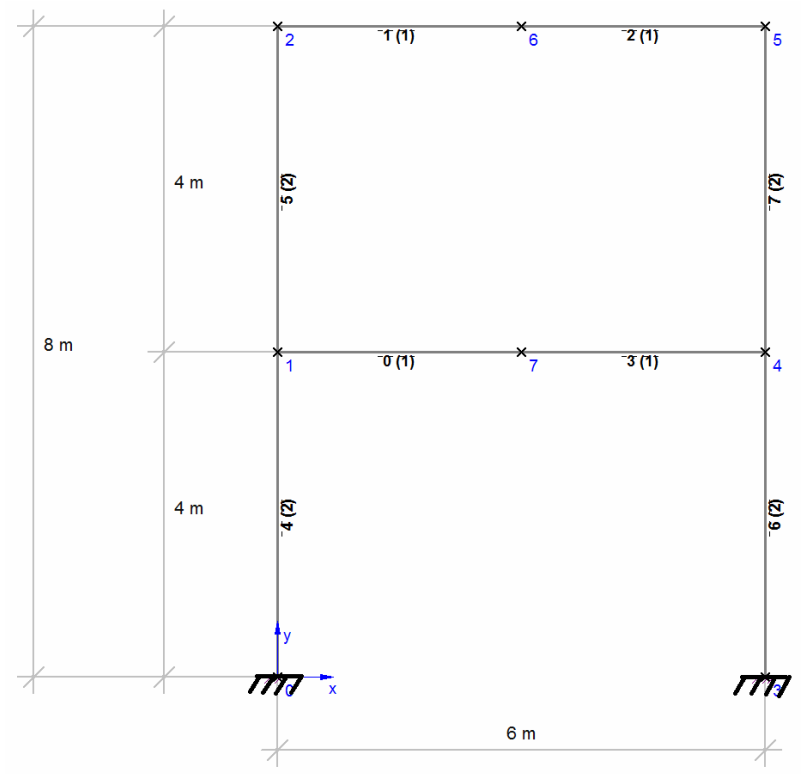

Figure 1. 2D-Model of the construction.



Figure 2. Cross-sections.
Concrete strength class is $\mathrm{C} 30 / 37$ and the reinforcement strength class is B500B. Main material parameters for linear and non-linear behaviour were defined according to [10, chapter 3.1 and 3.2. The most important parameters for the non-linear analysis of the concrete are compressive strength $f_{c k}=30 \mathrm{MPa}$, tension strength ( $5 \%$ fractile) $f_{c t k 0,05}=2.0 \mathrm{MPa}$ and design strain $\varepsilon_{c d}=0.077 \%$. For the reinforcement are the most important yield strength $f_{y k}=f_{t k}=500 \mathrm{MPa}$ and strain $\varepsilon_{y k}=2.5 \%$.

\section{2. $\mathrm{LOAD}$}

\subsubsection{VERTICAL LOAD}

The frame is loaded by the self-weight $(6 \mathrm{kN} / \mathrm{m}$ for the cross-beam and $4 \mathrm{kN} / \mathrm{m}$ for the column) and a uniformly distributed load $10 \mathrm{kN} / \mathrm{m}$, which represents fittings and imposed loads together. For the simplification, only one load for one combination was defined. Safety factors are not considered as well.

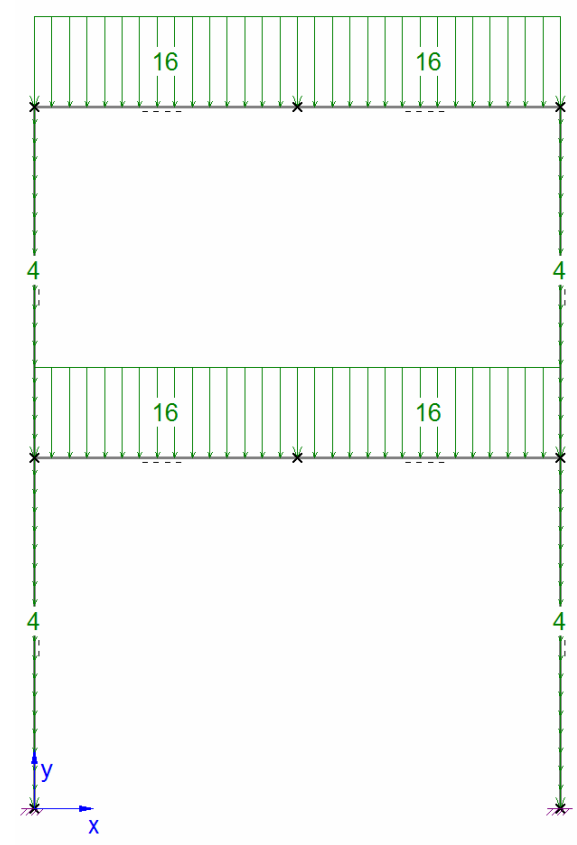

Figure 3. Vertical load.

\subsubsection{SEISMIC LOAD}

Seismic load was represented by horizontal elastic response spectrum, which is defined in 1, chapter 3.2.2.2. Initial conditions were chosen randomly, because the structure is fictional.

The design peak ground acceleration (PGA) is $0.8 \mathrm{~m} / \mathrm{s}$, that is $0.0815 \mathrm{~g}$. The response spectrum is Type 1, which corresponds in the Czech Republic to the Moravia and Silesia. The frame is based in the ground type $\mathrm{B}$, which corresponds to the very dense sand, gravel, or very stiff clay, with the average shear wave velocity $v_{s, 30}=360 \mathrm{~m} / \mathrm{s}$. The importance class of the structure is Class II, which describes ordinary buildings with the importance factor $\gamma, \mathrm{I}=1.0$.

Because the comparison has to follow the original response of the structure, it was necessary to use the 


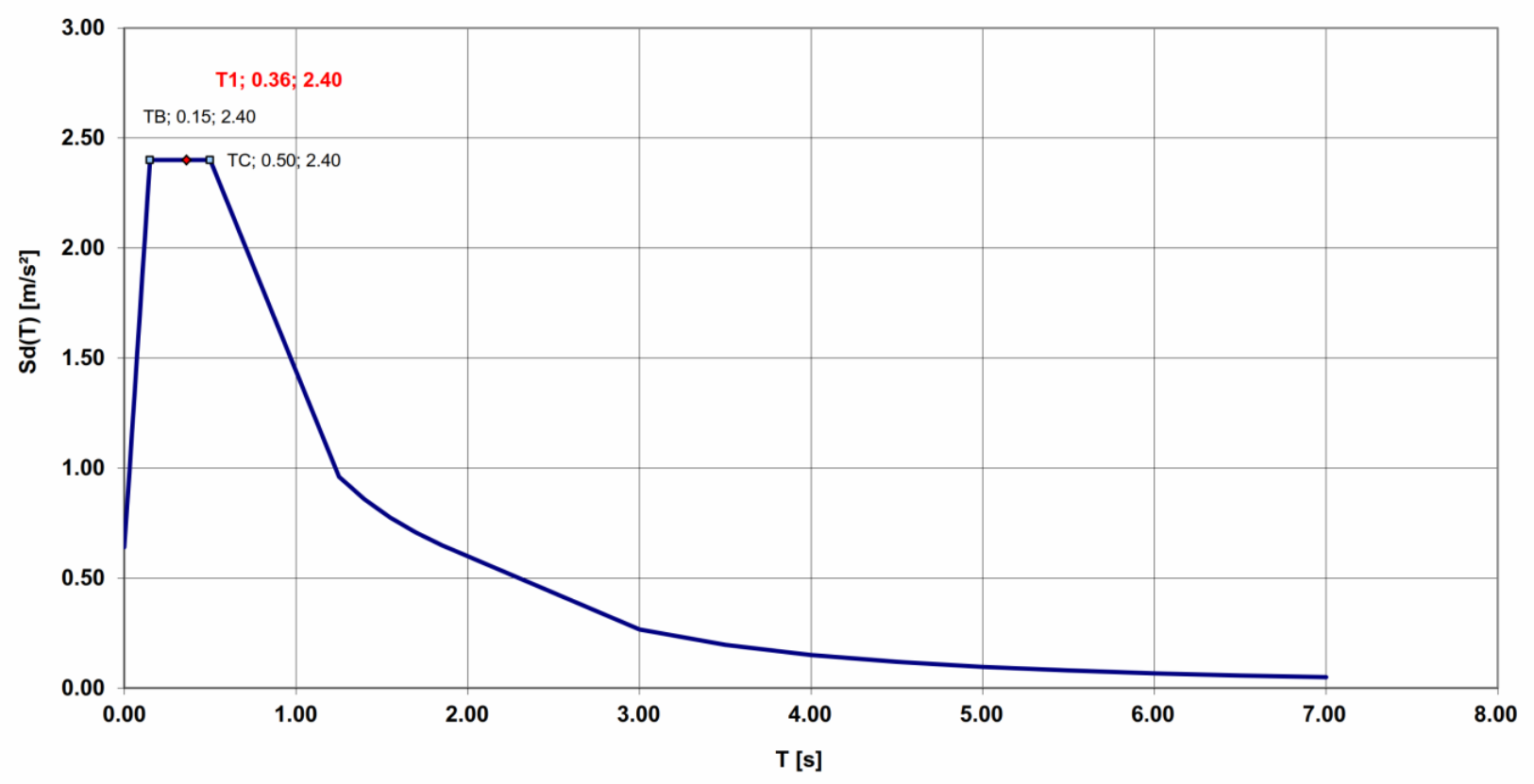

Figure 4. Horizontal elastic response spectrum.

behaviour factor $q=1$. With the behaviour factor $q=1$, it cannot to occur to an undesirable dissipation of the energy and to the change of the result. The effective damping $(\xi)$ follows the recommendation of the standard [1] and it is $\xi=5 \%$, which implies that the damping correction factor is equal to $1(\eta=1)$.

\subsection{SOFTWARE}

For following calculations was necessary to use some software:

- For the definition of the accelerogram, a programm SeismoArtif [1] was used. SeismoArtif [1] is made by the company Seismosoft (Pavia, Italy). This programm allows a conversion of the response spectrum to the one or more accelerograms. Accelerograms are used for the time-history analysis.

- For calculations with accelerograms, a programm SeismoStruct 12 was used. This programm is made by Seismosoft as well. SeismoStruct [12] uses the finite element method (FEM) and can use material and geometrical nonlinearities of the structure. SeismoStruct [12] was used for calculations of the eigenvalues, eigenmodes and seismic response.

- For the pushover analysis, a programm Stab2DNL [13] was used. This programm is made by Dr. Uwe Pfeiffer from University in Hamburg. Stab2D-NL [13] can compute 2D frames with the finite element method including material and geometrical nonlinearities. This software can consider the third-order-analysis as well.

\section{DyNAMiC PROPERTIES OF THE STRUCTURE}

\subsection{Eigenmodes}

For the first rough estimation of eigenmodes, a simplified method which neglects all deformations of the cross-beam can be used. That means the crossbeam has an infinite stiffness. This simplification allows to analyse the structure as a system with two degrees of freedom. Computational model is now a cantilever with two masses. The first eigenfrequency is $f_{0,1}=6.62 \mathrm{~Hz}$ and the second eigenfrequency is $f_{0,2}=16.87 \mathrm{~Hz}$. Eigenmodes were normalized to the roof level. The first eigenmode is defined as $\Phi_{1}=(0.632 ; 1)^{\mathrm{T}}$ and the second mode is $\Phi_{2}=(-1.383 ; 1)^{\mathrm{T}}$. Figure 5 shows the first and the second eigenmodes.
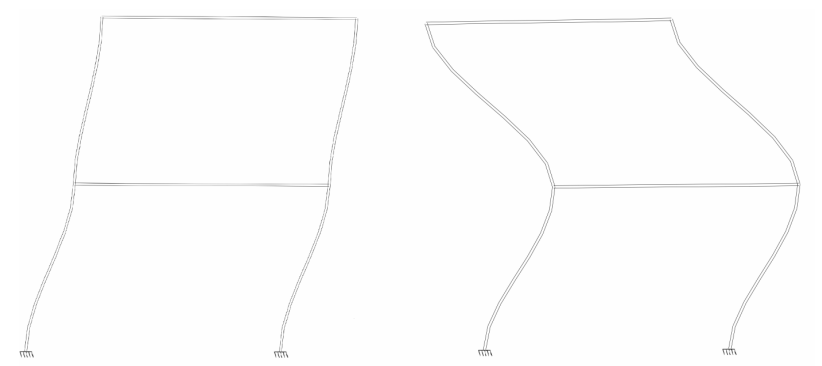

Figure 5. The first and the second eigenmode.

\subsection{Eigenmodes - FEM}

(1.) Frame with flexible beams

(2.) Frame with rigid beams

For following calculations, an infinitely stiff model was chosen. This effect was defined with a very high 


\begin{tabular}{lcc}
\hline Eigenmode & 1 & 2 \\
\hline Eigenfrequency $[\mathbf{H z}]$ & 5.830 & 15.853 \\
\hline Eigenperiod $[\mathbf{s}]$ & 0.1715 & 0.0631 \\
\hline Effective modal mass & 92.50 & 7.49 \\
$W_{x i} / W_{x, t o t}[\%]$ & $\Sigma$ & \multicolumn{2}{c}{99.99} \\
\hline
\end{tabular}

TABLE 1. Eigenvalue properties of the pliable stiff cross-beam.

stiffness of the cross-beam, specifically with the enlargement of the E-modulus in factor 40. From this moment are eigenvalues almost constant.

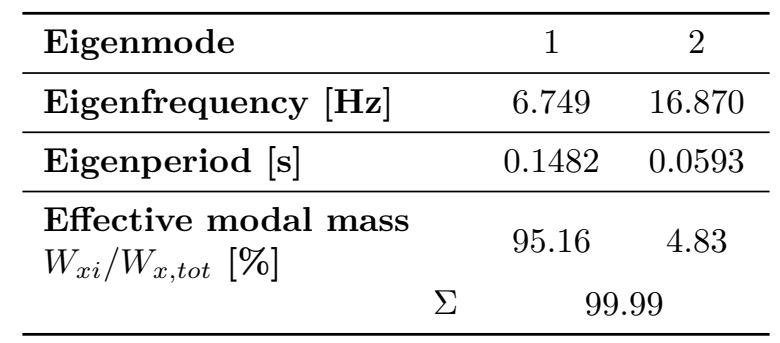

TABLE 2. Eigenvalue properties of the infinitely stiff cross-beam.

\section{LATERAL FORCE METHOD OF ANALYSIS}

This method is a static analysis using linear behaviour of the material, where horizontal forces represent the seismic load act to the joints of the structure. It is possible to use this method only for structures with small relevant eigenmodes. This method is used for a direct design of the cross-section, mostly from concrete and steel [14].

For this calculation, a proceeding according to 1, chapter 4.3.3.2 was used. The most important results are the design spectrum $S_{d(T 1)}=2.4 \mathrm{~m} / \mathrm{s}^{2}$ and the base shear force $F_{b}=57.6 \mathrm{kN}$. These values approach to horizontal forces acting on all storeys. The force for the first storey is $F_{1}=24.16 \mathrm{kN}$ and for the roof level is $F_{2}=33.44 \mathrm{kN}$.

Values $\Phi_{1}$ and $\Phi_{2}$ were assumed from the hand calculation in the chapter 3.1. Final horizontal displacements are $u_{1}=0.00109 \mathrm{~m}$ for the first storey and $u_{2}=0.001724 \mathrm{~m}$ for the second one.

\section{Modal RESPOnSE SPECTRUM ANALYSIS}

\subsection{HAND CALCULATION}

Input values for the structure and the response spectrum are equivalent to calculations in chapters 2.2.2 and 3.1. In the first step, horizontal forces for the first eigenmode $F_{1}=22.98 \mathrm{kN}, F_{2}=31.78 \mathrm{kN}$ and for the second eigenmode $F_{1}=4.32 \mathrm{kN}, F_{2}=-2.73 \mathrm{kN}$ were defined.
In the second step, horizontal displacements for the first eigenmode $u_{1}=0.001037 \mathrm{~m}, u_{2}=0.00003 \mathrm{~m}$, and for the second eigenmode $u_{1}=0.00003 \mathrm{~m}$, $u_{2}=0.000022 \mathrm{~m}$ were derived. From these results of the both eigenmodes, the total displacement was calculated. SRSS method was used for the combination of displacements and target results are $u_{1}=0.001038 \mathrm{~m}$ a $u_{2}=0.001639 \mathrm{~m}$.

Results show that the effect of the second eigenmode is marginal. As a proof, a calculation of effective modal masses can be used $-M_{1}^{\text {eff }}=22.815$ and $M_{2}^{\text {eff }}=1.184$.

\subsection{FEM - LINEAR}

Horizontal displacements were analysed by the FEM program with linear material behaviour of two versions:

(1.) Frame with flexible beams

$$
\begin{aligned}
& u_{k, \max }=0.00209002 \mathrm{~m}, \\
& u_{k, \min }=-0.00230263 \mathrm{~m} .
\end{aligned}
$$

(2.) Frame with rigid beams

$$
u_{k, \max }=0.00157214 \mathrm{~m} \text {, }
$$$$
u_{k, \min }=-0.00158202 \mathrm{~m} \text {. }
$$

\section{TIME-HISTORY ANALYSIS}

The time-history analysis is another option, how the seismic response can be calculated. A model for this calculation is imposed by up to three different accelerograms which describe the behaviour for each direction. Usually is this method used as non-linear analysis.

To compare this method with two linear methods is necessary to use synthetic accelerograms. These accelerograms describe the response spectrum. EC8 [1] defines, that for the determination of the design seismic action, an average value from at least seven nonlinear calculations has to be used. By fever calculations, the worst result has to be chosen.

Calculation of motion equations is the main principle of this method and it is calculated by the modal analysis or by the direct integration. Modal analysis allows the calculation with only linear material behaviour. With the direct integration is possible to use material non-linearities.

\subsection{HORIZONTAL LOAD}

This method is usually used for a calculation of any past known earthquake with defined accelerogram. For this comparison, accelerograms from the spectrum have to be defined. In fact, it is a reverse procedure. For the simplification, only one accelerogram was chosen. Deformation calculated by this method has almost the same value as the result by the response spectrum method. The software SeismoArtif [11] was chosen to generate the optimal accelerogram. For the generation of synthetic accelerogram, a direct integration according to [15] (this method will be not described in this article) was used. 




Figure 6. Acceleration.

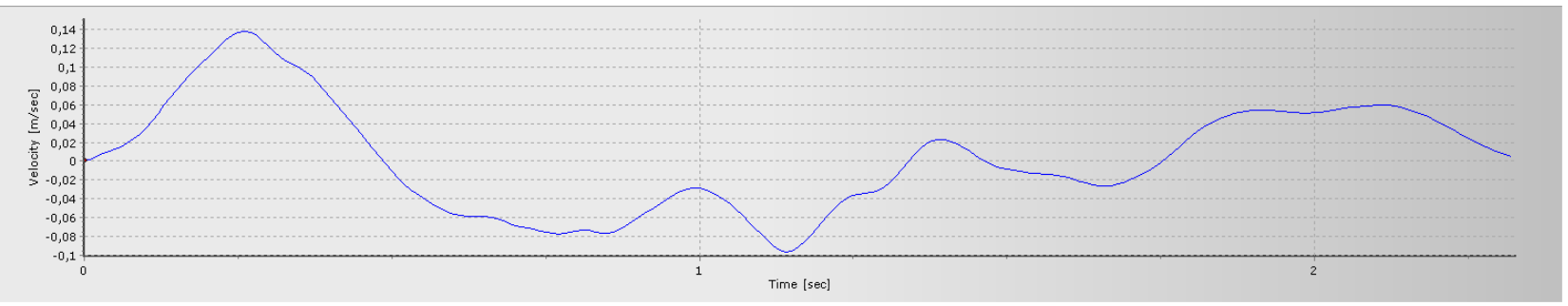

FiguRE 7. Velocity.

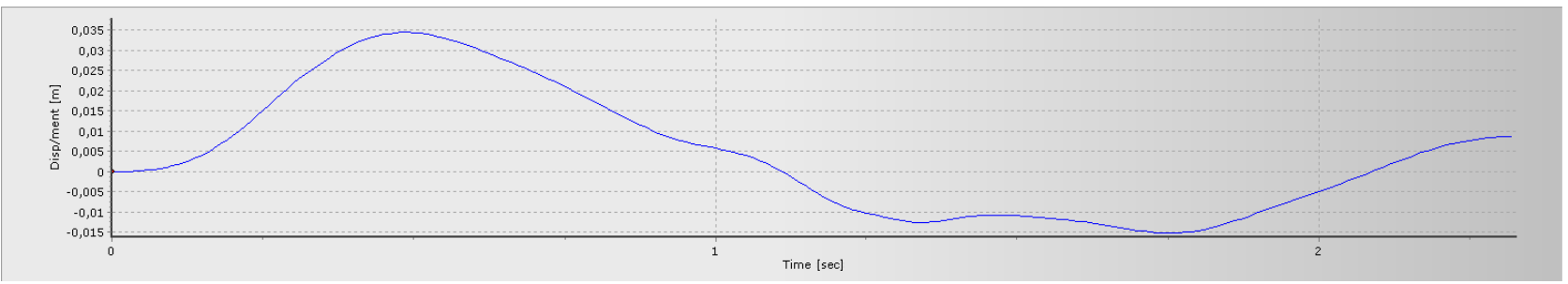

Figure 8. Displacement.

Input values for the generation of synthetic accelerogram by programm SeismoArtif [11]:

(1.) Response spectrum according to chapter 2.2 .2

(2.) Earthquake parameters

- Inter-plate regime of far-field

- Moment magnitude - 5

- Distance between the main event and the station $-5 \mathrm{~km}$

- Soil type - generic soil $\left(v_{s, 30}=310 \mathrm{~km} / \mathrm{s}\right)$

(3.) Generation of the synthetic accelerogram

- Smallest period of desired response spectrum $0.02 \mathrm{~s}$

- Largest period of desired response spectrum - $3 \mathrm{~s}$

- Damping - $5 \%$

- Time-step - $0.01 \mathrm{~s}$

- $\mathrm{PGA}-0.0815 g=0.8 \mathrm{~m} / \mathrm{s}$

\subsection{Comparison to the REsponse SPECTRUM}

Programm SeismoArtif [11] allows a comparison of time-history charts with the assigned response spectrum - Figures 9,10 and 11 .

\subsection{LINEAR TIME-HISTORY ANALYSIS}

Horizontal displacements were analysed by the FEM program SeismoStruct 12 for two versions of the structure.
(1.) Frame with flexible beams $u_{k, \max }=0.00236767 \mathrm{~m}$, $u_{k, \min }=-0.00283672 \mathrm{~m}$.

(2.) Frame with rigid beams

$$
u_{k, \max }=0.001553 \mathrm{~m} \text {, }
$$$$
u_{k, \min }=-0.001545 \mathrm{~m} \text {. }
$$

\subsection{NON-LINEAR TIME-HISTORY ANALYSIS}

Total horizontal displacement was calculated by the same software, but in this version, the non-linear material behaviour was used.

(1.) Frame with flexible beams

$u_{k, \max }=0.00238527 \mathrm{~m}$,

$u_{k, \min }=-0.00253367 \mathrm{~m}$. 


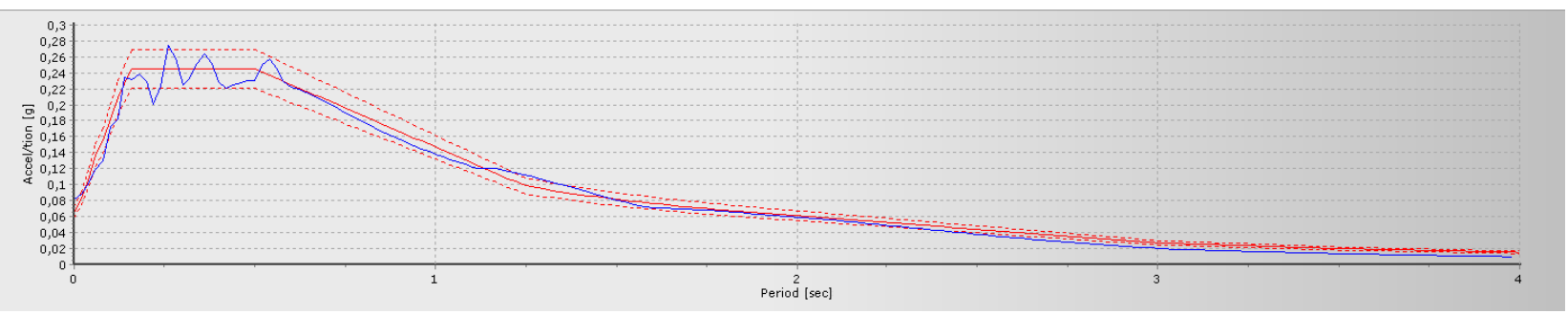

Figure 9. Comparison of the acceleration.

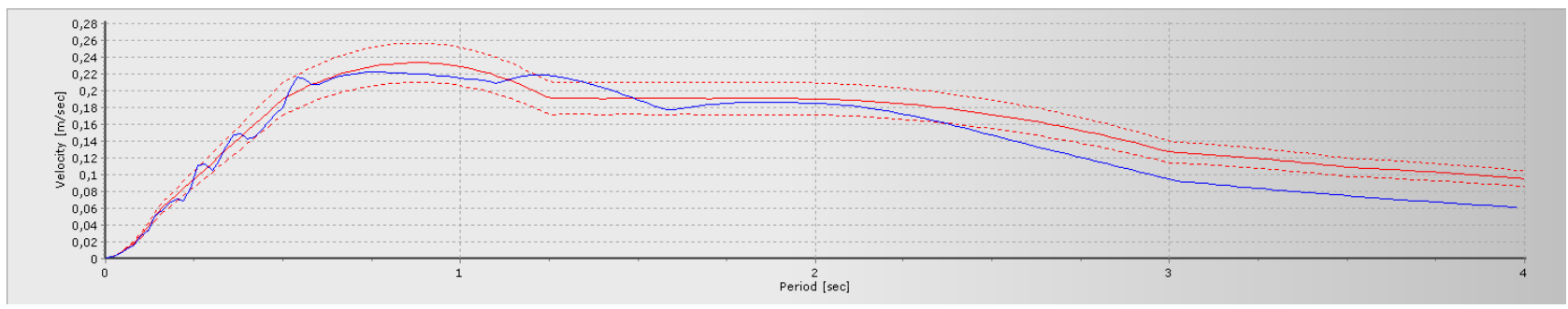

Figure 10. Comparison of the velocity.

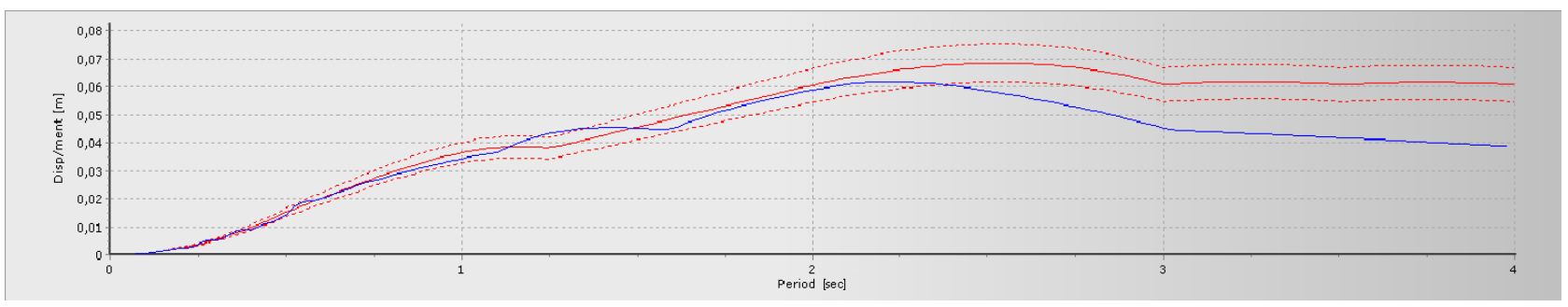

Figure 11. Comparison of the displacement.

(2.) Frame with rigid beams

$u_{k, \max }=0.00155074 \mathrm{~m}$,

$u_{k, \min }=-0.00154217 \mathrm{~m}$.

\section{Non-Linear StatiC (PUSHOVER) ANALYSIS}

Pushover analysis is the last method of the EC8 [1] for the calculation of the seismic response. This nonlinear method is based on constantly acting self-weight and monotonically increasing horizontal load. In this method, plastic mechanism has to be defined by plastic regions.

Sufficient ductility has to be ensured by good construction design of plastic regions. Remaining regions must have a big capacity and they have to stay elastic while plastic regions are overloaded. This procedure determines members for the energy dissipating. "Soft" regions are for dissipating and "hard" are elastic [14.

\subsection{HAND CALCULATIONS OF THE FRAME WITH FLEXIBLE BEAMS BY PUSHOVER ANALYSIS}

For determination of the pushover curve is necessary to monotonically increase the horizontal load up to the collapse of the structure or up to the maximal allowed horizontal displacement. According to [1] is necessary to applicate at least two different distributions of the lateral load (constant, linear, modal, ... ). For a simple comparison, only one distribution of the lateral load was used. In this case a modal distribution of the first eigenmode was chosen.

The PGA is $0.8 \mathrm{~m} / \mathrm{s}^{2}$. The product of the PGA and the total weight defines the base shear force $F_{b}=20.48 \mathrm{kN}$. The base shear force is distributed to the structure according to normalized eigenmodes.

Pushover curve describes the relation between the base shear force $F_{b}$ and the horizontal displacement $\mathrm{d}$ of the roof level. This capacity curve shows the yielding progress of the structure and regions of plastic hinges.

For calculation of the monotonically increasing load, the software Stab2D-NL 13 was chosen. Iterative non-linear calculation determined the maximal load by collapse of the structure by 7.4-times of the assigned lateral load $-F_{1}=60.83 \mathrm{kN}$ a $F_{2}=82.88 \mathrm{kN}$. Lateral load was increased in 50 steps, respectively by $2.0 \%$. Vertical load acts in all steps by $100 \%$. The collapse of the structure occurs by the depletion of the crosssection strength by the member Nr. 3. This method determines the capacity curve for the member Nr. 6 in the roof level.

Horizontal displacement of the multiple degree of freedom (MDOF) system in the roof level before collapse is $37.7 \mathrm{~mm}$. For the transformation to the single degree of freedom (SDOF) system is necessary to 




Figure 12. Example of the time-chart of the displacement.

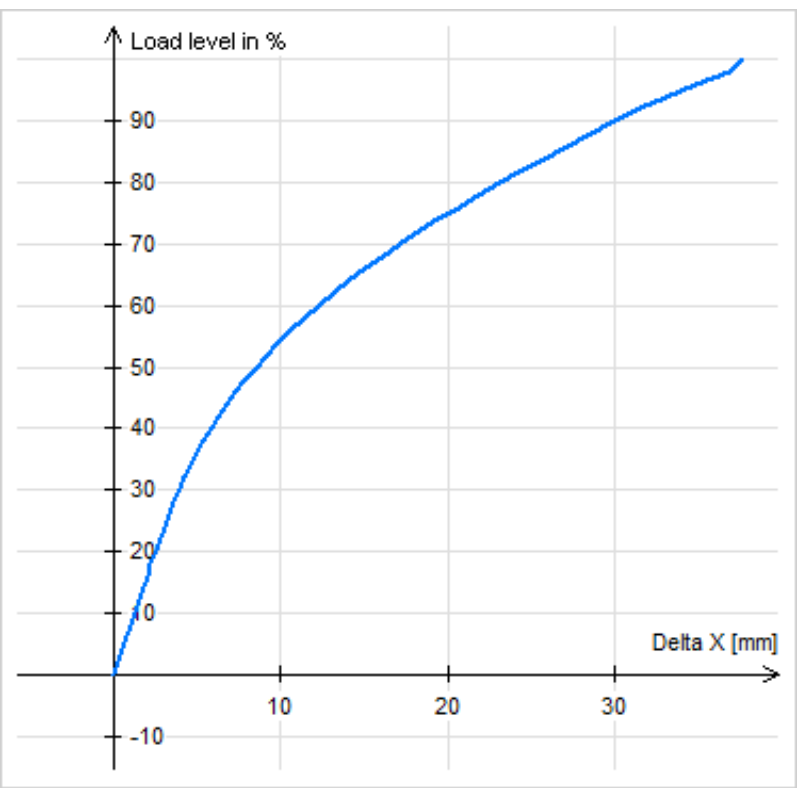

Figure 13. Capacity curve of the model with flexible beams.

determine transformation factor $\Gamma$. $\Gamma$ was counted according to procedure in [1], annex $\mathrm{B}$, and is equal to 1.127 .

Next step in this method is the determination of the deformation energy. Deformation energy is the surface under the capacity curve of SDOF system (Figure 13. This surface was calculated by integration of sextic equation which was defined by programm Excel (equation of the capacity curve). Deformation energy $E_{m}$ was transformed to the deformation energy of the SDOF system by transformation factor $\Gamma . E_{m}{ }^{*}$ is equal to $2875.07 \mathrm{kNmm}$.

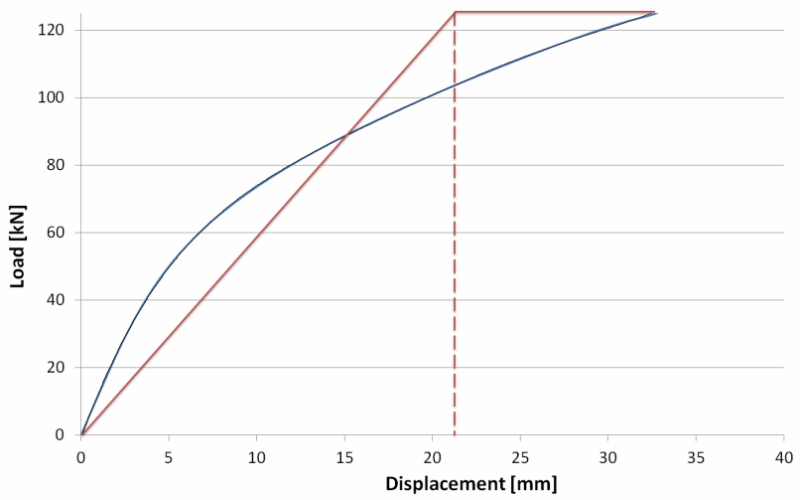

Figure 14. Determination of the idealized elastoperfectly plastic force-displacement relationship for the frame with flexible beams.

Determination of the idealized elasto-perfectly plastic force-displacement relationship is shown in Figure 14

The period of the idealized SDOF system was determined $\left(T^{*}=0.362 \mathrm{~s}\right)$. With this period, the horizontal displacement can be calculated. Because the period of the SDOF is smaller than the $T_{C}$-value of the response spectrum, a short period range can be considered. Because the calculated displacement of the SDOF was too far from the $d_{m}{ }^{*}$, iterative solution was used. After the fifth iteration, the target displacement is equal to $d *_{e t}=4.37 \mathrm{~mm}$. The displacement was transformed by the transformation factor to the target displacement of the MDOF system $-d_{t}=4.92 \mathrm{~mm}$. 


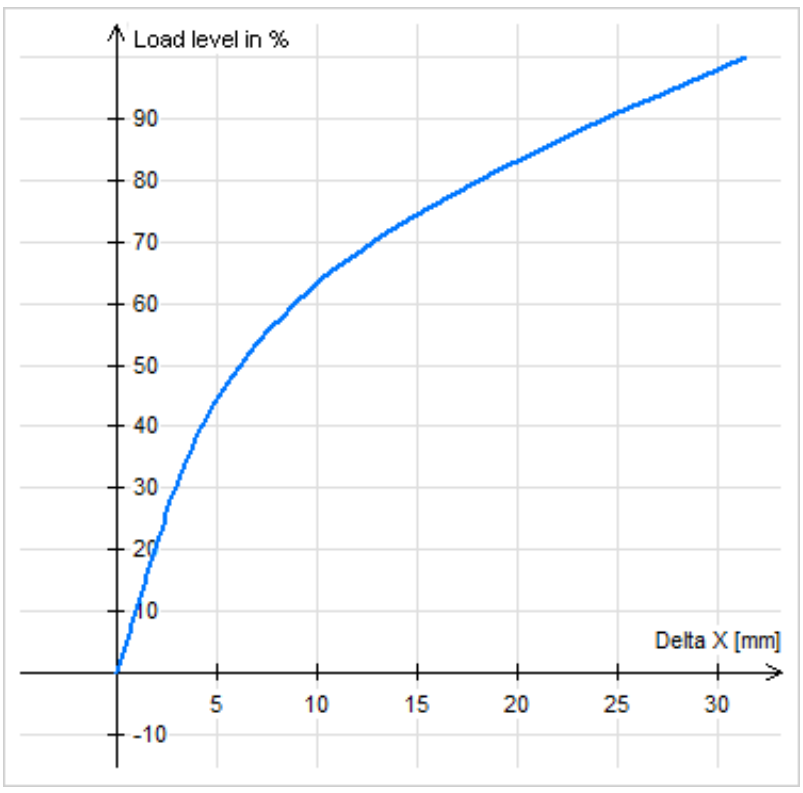

FIGURE 15. Capacity curve of the model with rigid beams.

\subsection{HAND CALCULATIONS OF THE FRAME WITH RIGID BEAMS BY PUSHOVER ANALYSIS}

The weight of the system stays identical. Distribution of lateral forces is changed with dependence on the stiffness. Collapse of the stiff structure occurs by the same member by 7.3-times of the assigned lateral load $-F_{1}=59.641 \mathrm{kN}$ a $F_{2}=81.76 \mathrm{kN}$. The capacity curve for the member Nr. 6 in the roof level was determined (Figure 15)

Horizontal displacement of the MDOF system in the roof level before collapse is $31.4 \mathrm{~mm}$. For the transformation to the SDOF system is necessary to determine transformation factor $\Gamma$. $\Gamma$ was counted according to procedure in [1], annex $\mathrm{B}$, and is equal to 1.129 .

Deformation energy $\mathrm{E}_{m}{ }^{*}$ was determined by the same procedure as in previous chapter. $E_{m}{ }^{*}$ is equal to $2428.84 \mathrm{kNmm}$. Determination of the idealized elasto-perfectly plastic force-displacement relationship is shown in Figure 16

The target displacement of the SDOF system was determined as in previous chapter. Six iterations were needed for the target displacement of the SDOF $d^{*}{ }_{e t}=3.02 \mathrm{~mm}$. The transformed displacement of the MDOF system is equal to $d_{t}=3.41 \mathrm{~mm}$.

\section{Comparison AND CONCLUSION}

All calculation methods for the seismic response according to EC8 1 were compared. A simple model of the two-storeyed frame was used. The main line of the comparison was in the following way:

- Hand calculations of dynamical characteristics were made.

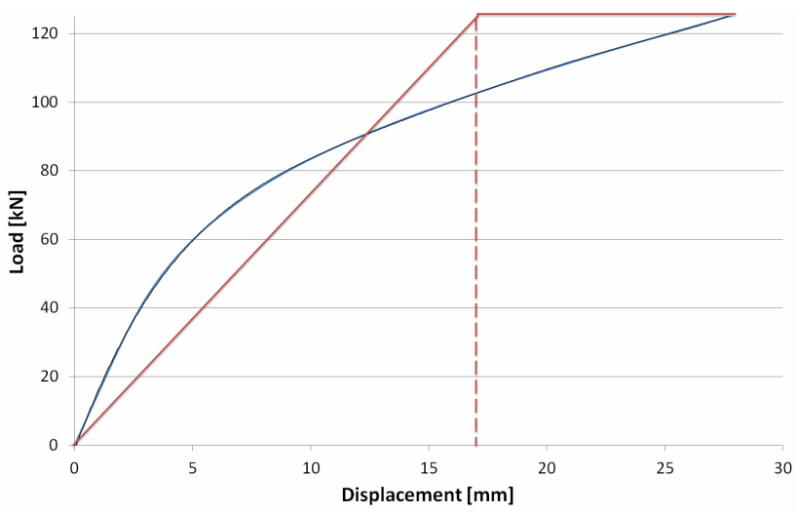

Figure 16. Determination of the idealized elastoperfectly plastic force - displacement relationship for the frame with rigid beams.

- These values were used for the hand calculation of the response from the spectrum.

- Results of the response spectrum were compared with software results.

- An accelerogram for time-history analysis with identical displacements to the response spectrum method was determined

- The chosen accelerogram was used for further calculations.

- Results were compared with lateral force method and pushover analysis.

All results correspond with the theory that the stiffer structure approaches to smaller deformations.

The lateral force method is the most conservative method for the seismic response. This method is used for simple symmetrical structures with predictable behaviour. The lateral force method is the simplest method and it is not necessary to use special software or complicated calculations. A disadvantage of this method is only linear material behaviour.

The next linear method is the response spectrum method. This method gave us better results. This is a good choice for more complicated structures. Members of the structure are with this analysis not so much oversized. It is widely used in the practice.

The non-linear behaviour changes results significantly. Non-linear methods according to EC8 [1] are the time-history analysis and the pushover analysis. Both of them are particular and it is necessary to use of some specialized software. The time-history analysis is suitable for the analysis of past known earthquakes. The pushover analysis is better for design of new structures or reconstructions. All results are compared in Table 3

Identical results of the horizontal displacement between linear calculations and dynamic calculation were achieved. On the other hand, a bigger difference between the pushover analysis and other methods was found out. This difference implies to a requirement to be cautious by this method and to focus on initial 


\begin{tabular}{lccc}
\hline \multirow{2}{*}{ Calculation method } & \multicolumn{2}{c}{ Horizontal displacement of the structure [mm] } \\
\cline { 2 - 4 } & Cross-beam stiffness & Linear & Non-linear \\
\hline \hline \multirow{2}{*}{ Lateral force method } & Flexible & - & - \\
& Rigid & $1.724^{d}$ & - \\
\hline \multirow{2}{*}{ Response spectrum method } & Flexible & $2.303^{a}$ & - \\
\hline \multirow{2}{*}{ Time-history analysis } & Rigid & $1.582^{a}, 1^{d .639^{d}}$ & $2.534^{b}$ \\
& Flexible & $2.837^{a}$ & $1.543^{b}$ \\
\hline \multirow{2}{*}{ Pushover analysis } & Rigid & $1.545^{a}$ & $4.92^{b, c}$ \\
& Flexible & - & $3.41^{b, c}$ \\
\hline
\end{tabular}

(a) Calculation by software SeismoStruct 12

(b) Calculation by software Stab2D-NL 13

(c) Hand calculation

TABLE 3. Comparison of calculations of the seismic response.

values. For these reasons, it is necessary to focus more on this method and to study another new conditions and inputs of its application.

\section{ACKNOWLEDGEMENTS}

The authors gratefully acknowledge support from the Czech Technical University in Prague, project SGS17/043/OHK1/1T/11 Development and application of advanced algorithms for numerical analysis and modelling of structures and materials.

\section{REFERENCES}

[1] En 1998-1: Eurocode 8: Design of structures for earthquake resistance: Part 1: General rules, seismic actions and rules for buildings, 2004.

[2] P. Bisch, E. Carvalho, H. Degee, et al. Eurocode 8: Seismic design of buildings: Worked examples. 1 Lisbon: Publications Office of the European Union 2012.

[3] A. Faroughi, M. Hosseini. Simplification of earthquake accelerograms for quick time history analyses by using their modified inverse fourier transforms. Procedia Engineering 14:2872-2877, 2011. DOI:10.1016/j.proeng.2011.07.361

[4] E. Kalkan, A. K. Chopra. Practical guidelines to select and scale earthquake records for nonlinear response history analysis of structures. US Geological Survey Open-File Report 2010.

[5] P. Fajfar, M. Fischinger. N2 - a method for non-linear seisimic analysis of regular buildings. Proceedings of Ninth World Conference on Earthquake Engineering pp. V111-V116, 1988. DOI:10.1002/eqe.144.
[6] A. K. Chopra, R. K. Goel. A modal pushover analysis procedure for estimating seismic demands for buildings. Earthquake Engineering 31(3):561-582, 2002. DOI:10.1002/eqe.144

[7] P. Fajfar. A nonlinear analysis method for performance based seismic design. Earthquake Spectra 16(3):573-592, 2000.

[8] V. Kilar, P. Fajfar. Simplified push-over analysis of building structures. Eleventh World Conference on Earthquake Engineering Acapulco (1011):2872-2877, 1996.

[9] M. Kreslin, P. Fajfar. The extended n2 method taking into account higher mode effects in elevation. Earthquake Engineering 40(14):1571-1589, 2011. DOI:10.1002/eqe.1104

[10] En 1992-1-1: Eurocode 2: Design of concrete structures: Part 1-1: General rules and rules for buildings, 2004.

[11] Programm seismoartif. http://www. seismosoft.com/seismoartif.

[12] Programm seismostruct. http://www. seismosoft.com/seismostruct

[13] Programm stab2d-nl. http://www.u-pfeiffer.de/

[14] H. Bachmann. Erdbebensicherung von Bauwerken. Basel - Boston - Berlin: Birkhäuser Verlag, 2002.

[15] B. Halldorsson. Calibration of the specific barrier model to earthquakes of different tectonic regions. Bulletin of the Seismological Society of America 95(4):1276-1300, 2005. DOI:10.1785/0120040157. 